\title{
Clinical significance of ADAM10 expression in laryngeal carcinoma
}

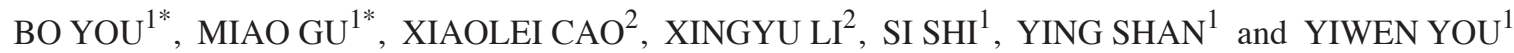 \\ ${ }^{1}$ Department of Otorhinolaryngology, Head and Neck Surgery, Affiliated Hospital of Nantong University; \\ ${ }^{2}$ Department of Pathology, Medical School of Nantong University, Nantong, Jiangsu 226001, P.R. China
}

Received June 23, 2015; Accepted October 24, 2016

DOI: $10.3892 / \mathrm{ol} .2016 .5546$

\begin{abstract}
Recent findings suggest that upregulated a disintegrin and metalloproteinase (ADAM)10 expression participates in the progression of multiple types of cancer. However, the expression pattern and clinicopathological significance of ADAM10, and its potential prognostic role in laryngeal carcinoma remains to be explored. The present study firstly determined the significantly elevated expression status of ADAM10 protein and messenger RNA in laryngeal carcinoma tissues compared with that in adjacent non-tumor tissues by western blotting and reverse transcription-quantitative polymerase chain reaction analysis. Next, the expression of ADAM10 and the proliferation marker $\mathrm{Ki}-67$ was examined in 78 laryngeal carcinoma and 35 adjacent non-tumor specimens using immunohistochemistry. Overexpressed ADAM10 in laryngeal carcinoma was detected, which correlated with $\mathrm{T}$ classification $(\mathrm{P}<0.01)$, clinical stage $(\mathrm{P}<0.01)$, pathology $(\mathrm{P}=0.034)$ and Ki-67 expression $(\mathrm{P}<0.01)$. Furthermore, the expression of ADAM10 was positively correlated with the expression of Ki-67 $\left(\mathrm{R}^{2}=0.22 ; \mathrm{P}<0.01\right)$. The Kaplan-Meier method revealed that the group with overexpressed ADAM10 exhibited shorter overall survival time compared with those with low ADAM10 expression. Our findings indicated that ADAM10 serves a notable role in the progression and prognosis of laryngeal carcinoma.
\end{abstract}

\section{Introduction}

Laryngeal cancer is estimated to be the second most common malignancy of the head and neck, and it has a high mortality rate and a poor prognosis $(1,2)$. The majority of laryngeal

Correspondence to: Dr Yiwen You, Department of Otorhinolaryngology, Head and Neck Surgery, Affiliated Hospital of Nantong University, 20 Xisi Road, Nantong, Jiangsu 226001, P.R. China

E-mail: youyiwen_nantong@163.com

${ }^{*}$ Contributed equally

Key words: ADAM10, laryngeal carcinoma, prognosis, immunohistochemistry, western blotting, RT-qPCR carcinoma patients are middle-aged males $(3,4)$. The primary risk factors are endogenic and exogenic factors such as tobacco smoking and alcohol consumption (4,5). Although multiple and advanced therapeutic interventions have been developed, the majority of laryngeal cancer patients present late to hospital, which leads to reduced therapeutic efficacy and increased rate of recurrence (2). Therefore, the development of highly efficacious treatments, as well as better diagnostic and preventive measures, require a better understanding of the molecular and pathogenic mechanisms of laryngeal cancer.

A disintegrins and metalloproteinases (ADAMs) are primarily located in the cell membrane, and have been shown to be involved in the proteolytic degradation of cell membrane proteins for remodelling or processing (6). Thus, ADAM family members, including ADAM10, serve pivotal roles in the pathogenesis or progression of cancers, including proliferation, angiogenesis, migration and invasion (6-9). Analysis of gene expression profiles revealed that the ADAM10 gene was significantly overexpressed in a wide variety of human malignancies, including hepatocellular carcinoma, melanoma, oral squamous cell carcinoma, lung cancer, pancreatic carcinoma, and gastric and bladder cancer (10-17). Accumulating evidence has illustrated that ADAM10 contributed to the regulation of cancer progression, chemoresistance and metastasis via the cleavage of growth factors or cell surface proteins $(6,8,10,12,18-21)$. Recently, it was reported that ADAM10 is overexpressed in hepatocellular carcinoma tissues, and that there are significant associations between ADAM10 expression levels and tumor grade, tumor differentiation, tumor size and metastasis (10). However, the involvement of ADAM10 in human laryngeal carcinoma remains unclear.

The present study firstly detected the expression pattern of ADAM10 in laryngeal carcinoma, and revealed that upregulated ADAM10 is strongly associated with T classification, clinical stage, pathology, Ki-67 expression and short survival in laryngeal carcinoma patients.

\section{Materials and methods}

Tissue specimens. A total of 78 laryngeal carcinoma tissue samples and 35 adjacent non-tumor tissues were collected from a cohort of laryngeal carcinoma patients following surgical excision at the Department of Otolaryngology, Head and Neck Surgery, Affiliated Hospital of Nantong University (Nantong, 
China) between January 2005 and December 2014. Informed consent was obtained from all patients. The clinicopathological characteristics of the patients are presented in Table I. All 78 laryngeal carcinoma patients included 72 males and 6 females aged $47-83$ years old (mean age, 67.9 years). The follow-up time was 80 months (follow-up period range, 12-80 months), and the median clinical follow-up time was 65 months. A total of 20 paired fresh laryngeal carcinoma and adjacent non-tumor tissues were collected from the Affiliated Hospital of Nantong University, snap frozen in liquid nitrogen and stored at $-80^{\circ} \mathrm{C}$ until use. None of the patients had received any therapy prior to surgery. Ethics approval to perform the current study was obtained from the Affiliated Hospital of Nantong University.

Immunohistochemical staining. Immunohistochemical analysis was performed as described previously (22). The sections were incubated with anti-ADAM10 antibody (diluted 1:100; Sangon Biotech, Co., Ltd., Shanghai, China) and anti-Ki-67 antibody (diluted 1:100; Santa Cruz Biotechnology, Inc., Dallas, TX, USA) overnight at $4^{\circ} \mathrm{C}$. Appropriate positive and negative controls were processed in parallel. VECTASTAIN ${ }^{\circledR}$ Elite ABC kit (Vector Laboratories, Inc., Burlingame, CA, USA) and 3,3'-diaminobenzidine were used to detect the binding of the primary antibody and to visualize the reaction, respectively.

Three blinded pathologists evaluated the immunohistochemistry scoring results independently. Immunostaining of ADAM10 was scored semiquantitatively in each tumor section based on the intensity and percentage of staining (17). Cytoplasmic immunostaining in tumor cells was considered to be positive. The staining intensity was assessed as strong $=2$; weak $=1$; and negative $=0$. The percentage of staining was categorized as follows: $0 \%$ of cells $=0 ; 1-25 \%$ of cells $=1 ; 26-50 \%$ of cells $=2 ; 51-75 \%$ of cells $=3$; and $>75 \%$ of cells $=4$. A final immunoreactivity score of $0-8$ was obtained for each section by multiplying the intensity score by the percentage score. Tumor samples with a final score $<4$ were regarded as negative or weak staining, while tumor samples with a final score of 4-8 were considered as ADAM10 overexpression. When evaluating Ki-67 expression, $51-100 \%$ of positively stained cell nuclei was regarded as high-expression group, while $0-50 \%$ was considered as low-expression group.

Western blot analysis. Total proteins were harvested with lysis buffer (Pierce; Thermo Fisher Scientific, Inc., Waltham, MA, USA) and quantified with the Pierce BCA Protein Assay kit (Thermo Fisher Scientific, Inc.). In total, $20 \mu \mathrm{g}$ protein per lane was separated by SDS-PAGE and transferred to polyvinylidene difluoride membranes. The membranes were blocked with $10 \%$ dried skim milk for $1 \mathrm{~h}$ at room temperature. Then, primary antibodies were used for immunoblot analysis against ADAM10 (1:300; D221496-0100; Sangon Biotech, Co., Ltd.) and $\beta$-actin (1:2,000; sc-47778; Santa Cruz Biotechnology, Inc.), overnight at $4^{\circ} \mathrm{C}$. Then, horseradish peroxidase-linked immunoglobulin G (1:5,000; sc-2374; Santa Cruz Biotechnology, Inc.) was used as the secondary antibody at room temperature for $1.5 \mathrm{~h}$. Immunoreactive bands were visualized by chemiluminescence (NEN; Life Science Products, Boston, MA, USA).
Reverse transcription-quantitative polymerase chain reaction $(R T-q P C R)$. Total RNA from frozen tissues was extracted using a TRIzol extraction kit (Sangon Biotech, Co., Ltd.), and then subjected to RT to covert it into complementary DNA using a Transcriptor First Strand cDNA Synthesis kit (Roche Diagnostics GmbH, Mannheim, Germany). The primers were purchased from Sangon Biotech Co., Ltd., and their sequences were as follows: ADAM10 forward primer, 5'-ATGGATTGT GGCTCATTGGT-3' and reverse primer, 5'-TGCCTGGAA GTGGTTTAGGA-3'; and GAPDH forward primer, 5'-GAA GGTGAAGGTCGGAGTC-3' and reverse primer, 5'-GAA GATGGTGATGGGATTTC-3'. The PCR cycling conditions were as follows: $42^{\circ} \mathrm{C}$ for $30 \mathrm{~min}$, followed by 36 cycles of amplification $\left(94^{\circ} \mathrm{C}\right.$ for $20 \mathrm{sec}, 58^{\circ} \mathrm{C}$ for $20 \mathrm{sec}$ and $72^{\circ} \mathrm{C}$ for $30 \mathrm{sec}$ ). Melting curve analysis was performed to assess the specificity and identity of the RT-qPCR products. The experiment was conducted in triplicate. GAPDH served as the internal control for messenger RNA (mRNA) determination of ADAM10. The results were normalized with the corresponding internal controls. The relative genomic expression was calculated by the $2^{-\Delta \Delta \mathrm{Cq}}$ method (23).

Calculation and statistical analysis. The data were analyzed with SPSS 17.0 software (SPSS, Inc., Chicago, IL, USA). The results were shown as means \pm standard deviation, and the Student's $t$-test was used to determine the statistical significance. Survival curves were estimated by the Kaplan-Meier method and compared by the log-rank test. Univariate and multivariate analyses were performed using Cox proportional hazards regression models. All statistical analysis were two-sided. $\mathrm{P}<0.05$ was considered to indicate a statistically significant difference.

\section{Results}

Analysis of ADAM10 expression in laryngeal carcinoma by western blotting and RT-qPCR. First, the expression level of ADAM10 was investigated in laryngeal carcinoma tissues compared with that in adjacent non-tumor tissues using western blotting and RT-qPCR. As shown in Fig. 1, both the protein and mRNA expression levels of ADAM10 were effectively higher in laryngeal carcinoma than in adjacent non-tumor tissues, although ADAM10 expression was variable among different pairs of laryngeal tissues (Fig. 1).

Detection of ADAM10 and Ki-67 expression in laryngeal carcinoma by immunohistochemistry. It was previously reported that overexpressed ADAM10 serves an important role in cancer cell proliferation (7). In the present study, immunohistochemistry was further performed to explore the expression of ADAM10 and the proliferation marker Ki-67 in laryngeal carcinoma (Fig. 2). Both ADAM10 and Ki-67 were highly expressed in laryngeal carcinoma compared with the levels detected in the adjacent non-tumor tissues (Fig. 2). The positive expression rate of ADAM10 is summarized in Table II. In brief, high ADAM10 expression was present in $62.82 \%$ (49/78) of laryngeal carcinoma tissues, while it was only present in $22.86 \%(8 / 35)$ of adjacent non-tumor tissues (Table II). The expression rate of Ki-67 was $57.69 \%(45 / 78)$ in laryngeal carcinoma tissues, while it was $31.43 \%(11 / 35)$ in 
Table I. Distribution of ADAM10 status in 78 human laryngeal carcinoma tissues according to clinicopathological characteristics.

\begin{tabular}{|c|c|c|c|c|}
\hline \multirow[b]{2}{*}{ Clinicopathological parameters } & \multirow[b]{2}{*}{$\mathrm{N}$} & \multicolumn{2}{|c|}{ ADAM10 expression, $\mathrm{n}$} & \multirow[b]{2}{*}{$\underline{\text { P-value }}$} \\
\hline & & Low & High & \\
\hline Gender & & & & 0.665 \\
\hline Male & 72 & 26 & 46 & \\
\hline Female & 6 & 3 & 3 & \\
\hline Age, years & & & & 0.456 \\
\hline$<60$ & 25 & 11 & 14 & \\
\hline$\geq 60$ & 53 & 18 & 35 & \\
\hline Tobacco smoking & & & & 0.122 \\
\hline No & 23 & 12 & 11 & \\
\hline Yes & 55 & 17 & 38 & \\
\hline T status & & & & $<0.010^{\mathrm{a}}$ \\
\hline $\mathrm{T} 1-\mathrm{T} 2$ & 47 & 23 & 24 & \\
\hline T3-T4 & 31 & 6 & 25 & \\
\hline Lymph node metastasis & & & & 0.065 \\
\hline No & 43 & 20 & 23 & \\
\hline Yes & 35 & 9 & 26 & \\
\hline TNM clinical stage & & & & $<0.010^{\mathrm{a}}$ \\
\hline I-II & 27 & 16 & 11 & \\
\hline III-IV & 51 & 13 & 38 & \\
\hline Pathology grade & & & & $0.034^{\mathrm{a}}$ \\
\hline Well/moderate & 47 & 22 & 25 & \\
\hline Poor/undifferentiated & 31 & 7 & 24 & \\
\hline \multicolumn{5}{|l|}{ Tumor location } \\
\hline Glottic & 47 & 18 & 29 & 0.883 \\
\hline Supraglottic & 24 & 9 & 15 & 0.879 \\
\hline Subglottic & 7 & 2 & 5 & 0.649 \\
\hline Ki-67 expression & & & & $<0.010^{\mathrm{a}}$ \\
\hline Low & 33 & 21 & 12 & \\
\hline High & 45 & 8 & 37 & \\
\hline
\end{tabular}

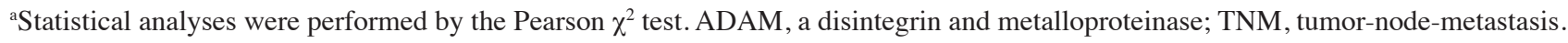

Table II. Expression of ADAM10 and Ki-67 in 78 laryngeal carcinoma and 35 tumor-adjacent normal tissues.

\begin{tabular}{|c|c|c|c|c|c|c|c|}
\hline \multirow[b]{2}{*}{ Tissues } & \multirow[b]{2}{*}{$\mathrm{N}$} & \multicolumn{2}{|c|}{ ADAM10, n (\%) } & \multicolumn{2}{|c|}{ Ki-67, n (\%) } & \multicolumn{2}{|c|}{ ADAM10/Ki-67, n (\%) } \\
\hline & & $+^{\mathrm{a}}$ & P-value & $t^{\mathrm{a}}$ & P-value & $+/+^{a}$ & P-value \\
\hline Laryngeal carcinoma tissues & 78 & $49(62.82)$ & $<0.01$ & $45(57.69)$ & 0.01 & 37 (47.44) & $<0.01$ \\
\hline Tumor-adjacent normal tissues & 35 & $8(22.86)$ & & $11(31.43)$ & & $3(8.57)$ & \\
\hline
\end{tabular}

${ }^{\mathrm{a}}+$ represents high expression, while +/+ represents high ADAM10 and high Ki-67 expression. ADAM, a disintegrin and metalloproteinase.

normal tissues (Table II). These results confirmed that both ADAM10 and Ki-67 exhibited higher expression levels in laryngeal carcinoma tissues than in non-tumor tissues.

Association between ADAM10 expression and clinicopathological characteristics in laryngeal carcinoma.
The association of ADAM10 expression level with clinicopathological factors of laryngeal carcinoma was evaluated. As shown in Table I, ADAM10 overexpression was significantly associated with $\mathrm{T}$ classification $(\mathrm{P}<0.01)$, clinical stage $(\mathrm{P}<0.01)$, pathology $(\mathrm{P}=0.034)$ and $\mathrm{Ki}-67$ expression $(\mathrm{P}<0.01)$. However, ADAM10 overexpression exhibited no significant 
A

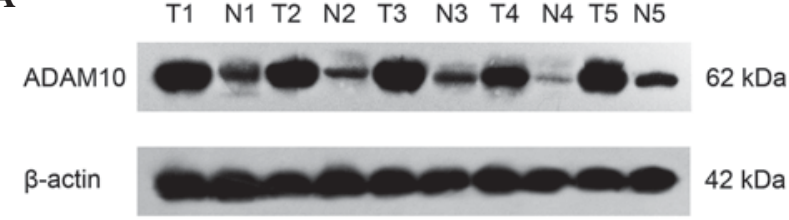

B

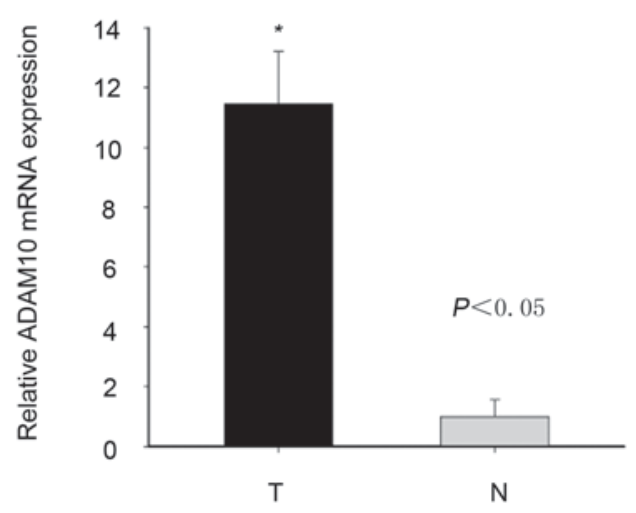

Figure 1. ADAM10 expression in laryngeal carcinoma tissues. (A) Analysis of the protein expression level of ADAM10 in 5 of 20 paired laryngeal carcinoma tissues by western blotting. (B) mRNA level of ADAM10 in 20 paired laryngeal carcinoma tissues, as determined by reverse transcription-quantitative polymerase chain reaction analysis. The experiments were repeated $\geq 3$ times. ${ }^{*} \mathrm{P}<0.05$. $\mathrm{T}$, laryngeal carcinoma tissues; $\mathrm{N}$, adjacent non-tumor tissues; ADAM, a disintegrin and metalloproteinase; mRNA, messenger RNA.

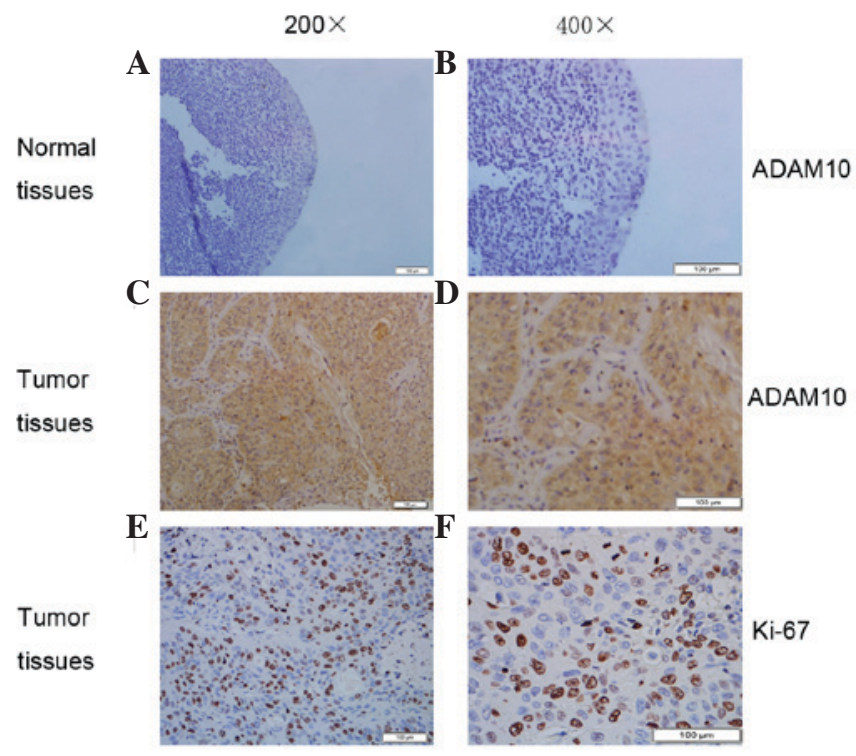

Figure 2. Immunohistochemistry findings of ADAM10 expression in laryngeal carcinoma tissues and adjacent non-tumor tissues. (A and B) Low expression of ADAM10 in adjacent non-tumor tissues (original magnification, x200 and x400, respectively). (C and D) ADAM10 immunohistochemical staining in laryngeal carcinoma tissues (original magnification, x200 and $\mathrm{x} 400$, respectively). (E and F) Ki-67 immunohistochemical staining in laryngeal carcinoma tissues (original magnification, x200 and x400, respectively) Scale bar, $100 \mu \mathrm{m}$. ADAM, a disintegrin and metalloproteinase.

association with other clinicopathological characteristics, including gender $(\mathrm{P}=0.665)$, age $(\mathrm{P}=0.456)$, tobacco smoking $(\mathrm{P}=0.122)$, lymph metastasis location $(\mathrm{P}=0.065)$ or tumor location (all $\mathrm{P}>0.05$ ). Furthermore, high expression of ADAM10

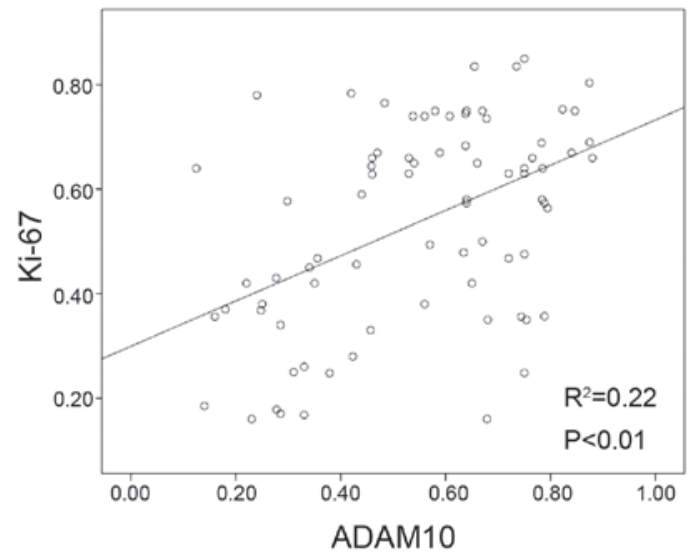

Figure 3. Association between Ki-67 proliferation index and ADAM10 expression in laryngeal carcinoma. Scatter plot of Ki-67 vs. ADAM10 expression with regression line revealed a correlation between them using the Spearman's correlation coefficient $(\mathrm{P}<0.01)$. ADAM, a disintegrin and metalloproteinase.

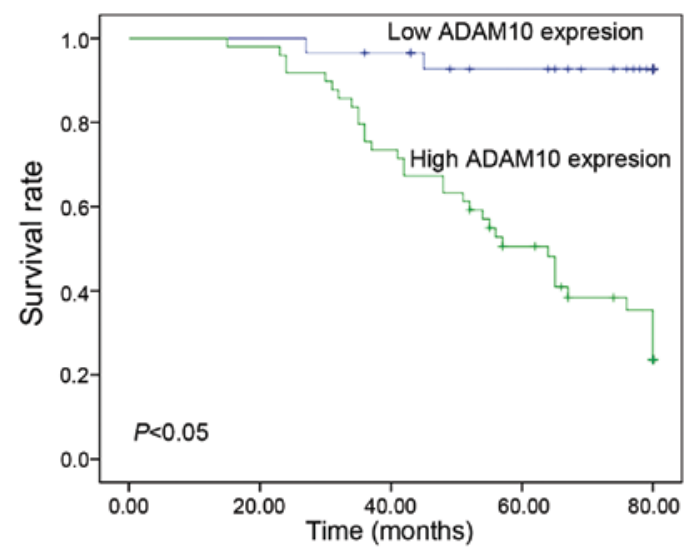

Figure 4. Kaplan-Meier survival curves of 78 patients with laryngeal carcinoma based on ADAM10 expression status. Patients in the high-expression group had significantly poorer prognosis than those in the low-expression group $(\mathrm{P}<0.05$, log-rank test). ADAM, a disintegrin and metalloproteinase.

was similar to that of Ki-67 in the majority of specimens (Table I). There was a positive correlation between ADAM10 expression and Ki-67-based proliferative activity $(\mathrm{P}<0.01$; Fig. 3).

ADAM10 expression is associated with survival of laryngeal carcinoma patients. Next, the prognostic value of ADAM10 expression in laryngeal carcinoma was assessed using Kaplan-Meier analysis with the log-rank test. It was observed that patients with ADAM10 overexpression exhibited significantly worse survival time than those with low ADAM10 expression $(\mathrm{P}<0.05)$ (Fig. 4). Univariate analyses revealed that the survival of laryngeal carcinoma patients was significantly correlated with $\mathrm{T}$ classification $(\mathrm{P}<0.01)$, lymph node metastasis $(\mathrm{P}=0.04)$, tumor-node-metastasis $(\mathrm{TNM})$ clinical stage $(\mathrm{P}<0.01), \mathrm{Ki}-67$ expression $(\mathrm{P}<0.01)$ and ADAM10 expression $(\mathrm{P}<0.01)$ (Table III). Multivariate analysis revealed that Ki-67 expression $(\mathrm{P}=0.034)$ and ADAM10 expression $(\mathrm{P}=0.030)$ were independent prognostic factors in laryngeal carcinoma patients (Table IV). 
Table III. Survival status and clinicopathological parameters in 78 human laryngeal carcinoma tissues.

\begin{tabular}{|c|c|c|c|c|}
\hline \multirow[b]{2}{*}{ Clinicopathological parameters } & \multirow[b]{2}{*}{$\mathrm{N}$} & \multicolumn{2}{|c|}{ Survival status, $\mathrm{n}$} & \multirow[b]{2}{*}{ P-value } \\
\hline & & Alive & Dead & \\
\hline Gender & & & & 0.406 \\
\hline Male & 72 & 40 & 32 & \\
\hline Female & 6 & 2 & 4 & \\
\hline Age, years & & & & 0.813 \\
\hline$<60$ & 25 & 14 & 11 & \\
\hline$\geq 60$ & 53 & 28 & 25 & \\
\hline Tobacco smoking & & & & 0.807 \\
\hline No & 23 & 13 & 10 & \\
\hline Yes & 55 & 29 & 26 & \\
\hline T classification & & & & $<0.010^{\mathrm{a}}$ \\
\hline T1-T2 & 47 & 33 & 14 & \\
\hline T3-T4 & 31 & 9 & 22 & \\
\hline Lymph node metastasis & & & & $0.040^{\mathrm{a}}$ \\
\hline No & 43 & 28 & 15 & \\
\hline Yes & 35 & 14 & 21 & \\
\hline TNM clinical stage & & & & $<0.010^{\mathrm{a}}$ \\
\hline I-II & 27 & 23 & 4 & \\
\hline III-IV & 51 & 19 & 32 & \\
\hline Pathology grade & & & & 0.107 \\
\hline Well/moderate & 47 & 29 & 18 & \\
\hline Poor/undifferentiated & 31 & 13 & 18 & \\
\hline \multicolumn{5}{|l|}{ Tumor location } \\
\hline Glottic & 47 & 25 & 22 & 0.762 \\
\hline Supraglottic & 24 & 14 & 10 & 0.762 \\
\hline Subglottic & 7 & 3 & 4 & 0.754 \\
\hline Ki-67 & & & & $<0.010^{\mathrm{a}}$ \\
\hline Low expression & 33 & 27 & 6 & \\
\hline High expression & 45 & 15 & 30 & \\
\hline ADAM10 & & & & $<0.010^{\mathrm{a}}$ \\
\hline Low expression & 29 & 27 & 2 & \\
\hline High expression & 49 & 15 & 34 & \\
\hline
\end{tabular}

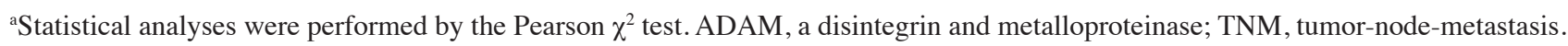

\section{Discussion}

The ADAMs are a family of proteins that contain an $\mathrm{N}$-terminal prodomain preceding a metalloproteinase domain, a disintegrin or integrin-binding domain, a cysteine-rich region, a transmembrane domain and an intracellular domain (24). ADAMs are involved in modulating the activity of diverse growth factors, receptors, membrane-bound cytokines and adhesion molecules by proteolytic cleavage, thus contributing to tumor developmental processes $(8,24)$. A number of ADAMs, including ADAM9, ADAM10, ADAM12 and ADAM17, are critical during the genesis, development and metastasis of cancers $(21,25,26)$. Dysregulated expression of ADAM10 has been reported in various malignancies, and has been suggested to be involved in cancer progression (10-17).
It has been demonstrated that downregulation of ADAM10 in HepG2 cells via small interfering RNA significantly suppressed cell proliferation, migration and invasion, and decreased chemotherapy drug resistance in vitro and tumor growth in vivo $(27,28)$, partially via reducing the constitutive phosphorylation of phosphoinositide 3-kinase and Akt (28). In addition, Maretzky et al reported that ADAM10 modulated the nuclear translocation of $\beta$-catenin through shedding of cadherin E, resulting in enhanced expression of cyclin D1 and c-Myc, thus leading to the promotion of proliferation (29). Furthermore, ADAM10 contribution to cell proliferation by increasing the transcriptional activity of $\beta$-catenin involves the action of receptor protein tyrosine phosphatases (30). In the present study, the expression and clinicopathological significance of ADAM10 in laryngeal 
Table IV. Contribution of various potential prognostic factors to survival by Cox regression analysis on 78 human laryngeal carcinoma patients.

\begin{tabular}{lccc}
\hline Variables & Hazard ratio & P-value & 95\% Confidence interval \\
\hline $\begin{array}{l}\text { T classification } \\
\text { T1-T2 vs. T3-T4 }\end{array}$ & 0.875 & 0.751 & $0.383-1.999$ \\
$\begin{array}{l}\text { Lymph node metastasis } \\
\text { No vs. yes }\end{array}$ & 0.854 & 0.694 & $0.388-1.877$ \\
$\begin{array}{l}\text { TNM clinical stage } \\
\text { I-II vs. III-IV }\end{array}$ & 3.466 & 0.079 & $0.867-13.858$ \\
$\begin{array}{l}\text { Ki-67 expression } \\
\text { Low vs. high }\end{array}$ & 2.766 & $0.034^{\mathrm{a}}$ & $1.080-7.083$ \\
$\begin{array}{l}\text { ADAM10 expression } \\
\text { Low vs. high }\end{array}$ & 0.178 & $0.030^{\mathrm{a}}$ & $0.037-0.842$ \\
\hline
\end{tabular}

Statistical analyses were performed by Cox regression analysis. ADAM, a disintegrin and metalloproteinase; TNM, tumor-node-metastasis .

carcinoma was characterized, particularly the prognostic function of ADAM10.

Our results indicated that ADAM10 expression was significantly higher in laryngeal carcinoma tissues compared with that in adjacent non-tumor tissues. This finding was consistent with that from previous studies on other tumors (10-17). Zhang et al reported that overexpression of ADAM10 in hepatocellular carcinoma tissues was significantly associated with tumor grade, tumor differentiation, tumor size and metastasis (10). The present study further analyzed the correlation of ADAM10 with clinical features of laryngeal carcinoma patients by immunohistochemistry. It was observed that high ADAM10 expression was associated with $\mathrm{T}$ classification, clinical stage, pathology and Ki-67 expression (all $\mathrm{P}<0.05$ ).

Previous reports indicated that ADAM10 overexpression is also involved with the poor prognosis of various malignancies, including hepatocellular carcinoma and gastric cancer $(10,16)$. In our study, Kaplan-Meier analysis also confirmed the prognostic value of ADAM10 in laryngeal carcinoma. Patients with ADAM10 overexpression exhibited poor prognosis and short survival time.

Univariate analysis revealed that patient's overall survival was significantly correlated with $\mathrm{T}$ classification $(\mathrm{P}<0.01)$, lymph node metastasis $(\mathrm{P}=0.04)$, TNM clinical stage $(\mathrm{P}<0.01)$, Ki-67 expression $(\mathrm{P}<0.01)$ and ADAM10 expression $(\mathrm{P}<0.01)$ (Table III). In addition, our multivariate analyses demonstrated that high expression of ADAM10 was a useful independent predictor of poor prognosis for laryngeal carcinoma, regardless of disease status. These findings suggested that ADAM10 expression may function as a oncogene and serve an important role in the development and progression of laryngeal carcinoma. In addition, high ADAM10 expression may serve as an independent prognostic biomarker of laryngeal carcinoma.

In summary, our data offered convincing evidence that ADAM10 is overexpressed in laryngeal carcinoma, and that high ADAM10 expression is involved in the aggressive malignant phenotype and poor prognosis of laryngeal carcinoma. Therefore, ADAM10 could serve as a potential independent prognostic factor for laryngeal carcinoma, and may be a novel therapeutic target for laryngeal carcinoma therapy using an RNA interference-based approach.

\section{Acknowledgements}

The present study was supported by grants from the Chinese National Natural Science Foundation (grant nos. 81172841, 81202368 and 81471603), the China Postdoctoral Science Foundation (grant no. 2013M541708), the Natural Science Foundation of Jiangsu Province (grant no. SBK2015022581), the '333 Natural Science Foundation' of Jiangsu (grant no. BRA2013286), the 'Top Six Types of Talents' Financial Assistance of Jiangsu Province (grant no. 6), the Jiangsu Provincial Health Department (grant no. Z201005), the Innovative Project of Nantong University Postgraduate Students (grant no. 13025043), the Jiangsu Province's Outstanding Medical Academic Leader Program (grant no. LJ201136) and the Administration of Science and Technology of Nantong (grant nos. BK2014007201 and BK2014003).

\section{References}

1. Jemal A, Bray F, Center MM, Ferlay J, Ward E and Forman D: Global cancer statistics. CA Cancer J Clin 61: 69-90, 2011.

2. Vokes EE and Stenson KM: Therapeutic options for laryngeal cancer. N Engl J Med 349: 2087-2089, 2003.

3. Mayne ST, Cartmel B, Kirsh V and Goodwin WJ Jr: Alcohol and tobacco use prediagnosis and postdiagnosis, and survival in a cohort of patients with early stage cancers of the oral cavity, pharynx, and larynx. Cancer Epidemiol Biomarkers Prev 18: 3368-3374, 2009.

4. Freedman ND, Abnet CC, Leitzmann MF, Hollenbeck AR and Schatzkin A: Prospective investigation of the cigarette smoking-head and neck cancer association by sex. Cancer 110: 1593-1601, 2007.

5. Sapkota A, Hsu CC, Zaridze D, Shangina O, Szeszenia-Dabrowska N, Mates D, Fabiánová E, Rudnai P, Janout V, Holcatova I, et al: Dietary risk factors for squamous cell carcinoma of the upper aerodigestive tract in central and eastern Europe. Cancer Causes Control 19: 1161-1170, 2008.

6. Klein T and Bischoff R: Active metalloproteases of the A Disintegrin and Metalloprotease (ADAM) family: Biological function and structure. J Proteome Res 10: 17-33, 2011.

7. Mochizuki S and Okada Y: ADAMs in cancer cell proliferation and progression. Cancer Sci 98: 621-628, 2007. 
8. Seals DF and Courtneidge SA: The ADAMs family of metalloproteases: Multidomain proteins with multiple functions. Genes Dev 17: 7-30, 2003.

9. Lu X, Lu D, Scully M and Kakkar V: ADAM proteins-therapeutic potential in cancer. Curr Cancer Drug Targets 8: 720-732, 2008.

10. Zhang W, Liu S, Liu K, Wang Y, Ji B, Zhang X and Liu Y: A disintegrin and metalloprotease (ADAM) 10 is highly expressed in hepatocellular carcinoma and is associated with tumour progression. J Int Med Res 42: 611-618, 2014.

11. Ko SY, Lin SC, Wong YK, Liu CJ, Chang KW and Liu TY: Increase of disintergin metalloprotease 10 (ADAM10) expression in oral squamous cell carcinoma. Cancer Lett 245: 33-43, 2007.

12. Lee SB, Schramme A, Doberstein K, Dummer R, Abdel-Bakky MS, Keller S, Altevogt P, Oh ST, Reichrath J, Oxmann D, et al: ADAM10 is upregulated in melanoma metastasis compared with primary melanoma. J Invest Dermatol 130: 763-773, 2010.

13. Guo J, He L, Yuan P, Wang P, Lu Y, Tong F, Wang Y, Yin Y, Tian J and Sun J: ADAM10 overexpression in human non-smal cell lung cancer correlates with cell migration and invasion through the activation of the Notch1 signaling pathway. Oncol Rep 28: 1709-1718, 2012.

14. Lendeckel U, Kohl J, Arndt M, Carl-McGrath S, Donat H and Röcken C: Increased expression of ADAM family members in human breast cancer and breast cancer cell lines. J Cancer Res Clin Oncol 131: 41-48, 2005.

15. Gaida MM, Haag N, Günther F, Tschaharganeh DF, Schirmacher P, Friess H, Giese NA, Schmidt J and Wente MN: Expression of A disintegrin and metalloprotease 10 in pancreatic carcinoma. Int J Mol Med 26: 281-288, 2010.

16. Wang YY, Ye ZY, Li L, Zhao ZS, Shao QS and Tao HQ: ADAM 10 is associated with gastric cancer progression and prognosis of patients. J Surg Oncol 103: 116-123, 2011.

17. Fu L, Liu N, Han Y, Xie C, Li Q and Wang E: ADAM10 regulates proliferation, invasion, and chemoresistance of bladder cancer cells. Tumour Biol 35: 9263-9268, 2014.

18. Yue Y, Shao Y, Luo Q, Shi L and Wang Z: Downregulation of ADAM10 expression inhibits metastasis and invasiveness of human hepatocellular carcinoma HepG2 cells. Biomed Res Int 2013: 434561, 2013
19. Zhao H, Zhu J, Cui K, Xu X, O'Brien M, Wong KK, Kesari S, Xia W and Wong ST: Bioluminescence imaging reveals inhibition of tumor cell proliferation by Alzheimer's amyloid beta protein. Cancer Cell Int 9: 15, 2009.

20. Endres K and Fahrenholz F: Upregulation of the alpha-secretase ADAM10-risk or reason for hope? FEBS J 277: 1585-1596, 2010

21. Lin T, Gu J, Zhang L, Davis JJ, Huang X, Cabbini G, Ji L and Fang B: Enhancing adenovirus-mediated gene transfer in vitro and in vivo by addition of protamine and hydrocortisone. J Gene Med 5: 868-875, 2003.

22. You Y, Yao H, You B, Li X, Ni H, Shi S, Shan Y and Cao X Clinical significance of HAX-1 expression in laryngeal carcinoma. Auris Nasus Larynx 42: 299-304, 2015.

23. Livak KJ and Schmittgen TD: Analysis of relative gene expression data using real-time quantitative PCR and the 2(-Delta Delta C(T)) method. Methods 25: 402-408, 2001.

24. Edwards DR, Handsley MM and Pennington CJ: The ADAM metalloproteinases. Mol Aspects Med 29: 258-289, 2008

25. Wu K, Liao M, Liu B and Deng Z: ADAM-17 over-expression in gallbladder carcinoma correlates with poor prognosis of patients. Med Oncol 28: 475-480, 2011.

26. Zubel A, Flechtenmacher C, Edler L and Alonso A: Expression of ADAM9 in CIN3 lesions and squamous cell carcinomas of the cervix. Gynecol Oncol 114: 332-336, 2009.

27. Liu S, Zhang W, Liu K, Ji B and Wang G: Silencing ADAM10 inhibits the in vitro and in vivo growth of hepatocellular carcinoma cancer cells. Mol Med Rep 11: 597-602, 2015.

28. Zhang W, Liu S, Liu K, Ji B, Wang Y and Liu Y: Knockout of ADAM10 enhances sorafenib antitumor activity of hepatocellular carcinoma in vitro and in vivo. Oncol Rep 32: 1913-1922, 2014.

29. Maretzky T, Reiss K, Ludwig A, Buchholz J, Scholz F, Proksch E, de Strooper B, Hartmann D and Saftig P: ADAM10 mediates E-cadherin shedding and regulates epithelial cell-cell adhesion, migration, and beta-catenin translocation. Proc Natl Acad Sci USA 102: 9182-9187, 2005.

30. Anders L, Mertins P, Lammich S, Murgia M, Hartmann D, Saftig P, Haass C and Ullrich A: Furin-, ADAM 10-, and gamma-secretase-mediated cleavage of a receptor tyrosine phosphatase and regulation of beta-catenin's transcriptional activity. Mol Cell Biol 26: 3917-3934, 2006. 